\title{
Introduction: Trends and Developments in the Pharmaceutical and Life Sciences Industry
}

\author{
Lars Schweizer and Theodor Dingermann
}

\begin{abstract}
Currently, the pharmaceutical industry is facing rapid changes occurring e.g. as a result of biotechnology's development, the raising importance of IT/Big data as well as new tailor-made gene therapies or the CRISPR/CAS technology. This chapter is based on the observation that the management and science in the pharmaceuticak industry is changing dramatically. The title of this book "Advances in Pharma Business Management and Research, Volume 1" reflects the diversity of the included studies and the goal to include and incorporate the different developments, trends, and challenges in the pharmaceutical industry. Thus, it comprises a number of interesting studies analyzing current challenges in the industry.
\end{abstract}

Currently, the pharmaceutical industry is facing rapid changes occurring e.g. as a result of biotechnology's development, the raising importance of IT/Big data as well as new tailor-made gene therapies or the CRISPR/CAS technology. One might ask why the pharmaceutical industry is so important and interesting. The simplest and most obvious answer lays in the most fundamental need of mankind: the will to survive. The discoveries in the pharmaceutical and biotechnology industries help to reduce mortality and to prolong life. This can surely be considered as one of the most important needs, if not the need and desire of all human beings.

Due to an oversight in editing, the second paragraph on page 3 was not removed, though it referred to an abstract which did not appear in this publication. We had asked the reader to ignore this section, and apologized for the error.

The original version of this chapter was revised. A correction to this chapter can be found at https://doi.org/10.1007/978-3-030-35918-8_8

L. Schweizer $(\bowtie)$

Chair for Strategic Management, Faculty of Economics and Business, Goethe-University

Frankfurt, Frankfurt, Germany

e-mail: 1.schweizer@em.uni-frankfurt.de

T. Dingermann

Faculty of Biochemistry, Institute for Pharmaceutical Biology, Goethe-University Frankfurt,

Frankfurt, Germany

L. Schweizer et al. (eds.), Advances in Pharma Business Management and Research, https://doi.org/10.1007/978-3-030-35918-8_1 
This book series is based on the observation that the management and science in the pharmaceutical industry is changing dramatically. Historically, competition in the pharmaceutical industry has been characterized by three factors. First, competitive advantage has been driven by blockbuster drugs, which were required to offset the cost of expensive hit-or-miss clinical trial programs. Second, almost all pharmaceutical companies have traditionally been vertically integrated from research and discovery through worldwide sales and marketing. Third, pharmaceutical companies have played a peripheral role as 'suppliers' in the health care system, provided marketing solutions to payers and providers. However, they had no intention in driving primary consumer demand or becoming involved in care, diagnosis, or decision-making.

Nowadays, pharmaceutical companies face daunting stock market expectations, short-term operating pressures on earnings, and increased regulatory requirements. As a result, pharmaceutical firms need to adjust their strategy in various ways. E.g., (1) they turn to mergers and acquisitions in order to plug strategic holes and accelerate operational improvements, (2) they enter into strategic alliances, and (3) they focus their activities on specific core areas. Hence, the future success will require pharmaceutical firms to develop new capabilities on many fronts. First, they have to dedicate resources in order to stay informed of technology developments and integrate the most promising technologies and (gene) therapies in-house. Second, the efficient storage and effective retrieval of the vast quantities of data provided by the new technologies have to be assured. Third, pharma companies will have to hire the right talent for each specific task and pay attention that they effectively work together. Fourth, development and marketing must continuously be informed over the advances in research and discovery, because they have to create targeted products for smaller subpopulations of diseases. Fifth, pharmaceutical companies will have to create more effective tools for portfolio selection and management.

Looking at the firm level, one needs to consider some additional trends and developments. (1) From a competitive perspective, biotechnology challenges the historical bases of competition (blockbuster drugs, vertical integration, role as supplier) in the pharmaceutical industry. (2) Knowledge and technology are not only transforming drug discovery, they are also redefining the business structure of the pharmaceutical industry. Many new players focus on narrow elements of the pharmaceutical business, from clinical trials to specialty manufacturing to genomic databases and screening capability. This trend is called deconstruction of the value chain leading to increased outsourcing activities. (3) Consumers are gaining more and more access to information and establishing greater control over decisions about their care. Accelerating progress in genetic understanding creates the possibility for pharmaceutical firms to segment patients on the basis of genomic descriptors and tailor therapy according to their specific needs. As a result pharmaceutical firms need to become more consumer-centric. 
The title of this book "Advances in Pharma Business Management and Research, Volume 1" reflects the diversity of the included studies and the goal to include and incorporate the different developments, trends, and challenges in the pharmaceutical industry. Thus, this book comprises a number of interesting studies analyzing current challenges in the industry.

To start with, Nadine Schneider is putting her focus on the regulatory environment. Her study is entitled "Relevance of instruments for measurements of Quality of Life in the AMNOG context", where she analyzed the endpoint "Health-related Quality of Life (HrQoL)" from different perspectives. Among the four outcomes "morbidity", "mortality", "adverse effects" and "HrQoL" the latter is the most subjective and also a relatively new outcome. This study covers in addition to standard analytical tools also interviews to investigate different perspectives regarding the relevance of this endpoint in comparison to the others. At the end it comes down to the question: "Is the endpoint $\mathrm{HrQoL}$ a fully equivalent outcome category within the assessment process in the AMNOG context?" This study was supervised by Dr. Matthias Pfannkuche.

The focus of Daria Mikhailova study is put on the firm-level. She analyzed "The quality management system for $R \& D$ project and portfolio management in a pharmaceutical company". She especially evaluated critically the relationships between elements of project quality and other project performance dimensions. She approached this question by adopting a systems perspective to quality and answering the question on how elements of a project management quality system are interrelated to achieve project excellence in a generic pharmaceutical research and development setting. Among other results Daria concluded that higher quality levels of project management processes help to eliminate trade-offs between project performance dimensions and decrease total cost of ownership of the developed products. This study was supervised by Dr. Hans Martin Schwarm.

The study of Johannes Heusler is entitled "Brexit and Its Impact on Pharmaceutical Law - Implications for global pharma companies". By that, he combines a macro- and a micro-level perspective analyzing the impact of the UK leaving the European Union on pharmaceutical firms with a special focus on the regulatory environment. The future development as well as the post-Brexit relationship between the UK and the EU are hard to predict. The study at hand provides a comprehensive evaluation of potential changes to the regulatory framework and their consequences, focusing on the following key areas: (1) Marketing authorizations and drug approval procedures, (2) Drug manufacturing: rules on Good Manufacturing Practice (GMP) and quality of pharmaceutical products, (3) Pharmacovigilance, as well as (4) Clinical trials. Based on his analysis, Johannes derives recommended actions like the installation of a Brexit Working Group within pharmaceutical firms in order to deal with the resulting challenges. This study was supervised by Dr. Ursula Schickel.

Gaining and retaining valuable human resources is a key and constant challenge for pharma firms. The study of Silke Baasner is entitled "Implementation of 
Measurable and Sustainable Actions to Improve Employee's Engagement and Business Performance - Global Medical Clinical \& Regulatory Affairs (GMCRA) - A Role Model at Fresenius Kabi" and deals with this challenge. In order to bring a high performance culture to life and to add value to the company the management of GMCRA at Fresenius Kabi has started the initiative Excellence@GMCRA. To evaluate the status regarding employee engagement a computer assisted web questionnaire on feedback culture at GMCRA, focusing on leadership behavior and staff development, was performed. The study at hand describes the results as well as the actions implemented by the management like (1) onboarding program for new employees with a buddy concept, (2) regular 1:1 meetings with superiors and employee, and (3) individual personal development plan (PDP) for each employee. As a result of these measures the bond of employees to the company was increased, the engagement of employees was fostered, and the performance of the employees were improved. This study was supervised by Dr. Fabian Urban.

The empirical study of Martin Lange and Alina Hernandez-Bark deals also with the increasing importance of human resources and organizational effectivity and efficiency as a key success factor for pharmaceutical firms. It is entitled "Leadership Models and Work Behavior: An Empirical Analysis of Consequences of Authentic and Transformational Leadership". Throughout the course of the 20th century, a multitude of empirical studies show primarily positive relationships between different constructs of leadership models and desirable variables of organizational behavior. However, the selection of analyzed leadership models and their consequences is very heterogeneous. The study at hand has the objective to contribute to Leadership Research by applying a comparative empirical study in the - until today - often neglected study population of in-house and sales personnel within the pharmaceutical industry. For this purpose, an online employee survey with $\mathrm{N}=137$ participants from a leading pharmaceutical company in Germany was conducted. Based on contemporary leadership theory, a range of Hypotheses regarding consequences of modern leadership models is empirically tested. The results of the study reconfirm Identification with Manager, Trust and Loyalty as well as Employee Satisfaction as consequences of Authentic and Transformational leadership. Work context as in-house vs. sales setting shows moderating effects on some of the leadership-consequences relationships.

The study of Elmar Hörner analyzes the management of intrafirm relationships in the form of strategic alliances-a collaboration form that has been increasing continuously and significantly since the beginning of the 1990 in the pharmaceutical industry. It is entitled "Alliance Management at Merck - Establishing an operational 100-day plan for alliance launches and management" and takes a firm-level perspective. This research is motivated by the observation that the pharmaceutical industry has been facing many challenges in the past 20 years leading to a change and adaptation in business models. One of the adaptions is the increasing importance and raising number of strategic alliances. The study at hand analyzes the launch phase of an alliance and proposes an operational 100-day plan for the use during 
different sub-phases in the context of the German pharmaceutical firm Merck KGaA based in Darmstadt. The focus is put on the role and skills of Alliance Management during the lifecycle of the partnership. This plan is validated by a survey with alliance managers at Merck KGaA and includes the following phases: (1) Preparation of Alliance Launch, (2) Alliance Launch/Develop Alliance Strategy, (3) Execute Alliance, (4) Evaluate Alliance Strategy, and (5) Managing the Alliance. This study was supervised by Dr. Eva Koscher.

Open Access This chapter is licensed under the terms of the Creative Commons Attribution 4.0 International License (http://creativecommons.org/licenses/by/4.0/), which permits use, sharing, adaptation, distribution and reproduction in any medium or format, as long as you give appropriate credit to the original author(s) and the source, provide a link to the Creative Commons licence and indicate if changes were made.

The images or other third party material in this chapter are included in the chapter's Creative Commons licence, unless indicated otherwise in a credit line to the material. If material is not included in the chapter's Creative Commons licence and your intended use is not permitted by statutory regulation or exceeds the permitted use, you will need to obtain permission directly from the copyright holder. 